\title{
Raman Spectroscopic Investigations into Links between Intrinsic Reactivity and Char Chemical Structure
}

\author{
Meijun Wang ${ }^{1,2}$, Daniel Roberts ${ }^{1 *}$, Mark Kochanek ${ }^{1}$, David Harris ${ }^{1}$, \\ Liping Chang ${ }^{2}$, Chun-Zhu $\mathrm{Li}^{3}$
}

\begin{abstract}
${ }^{1}$ CSIRO Energy Technology, PO Box 883, Kenmore, QLD 4069, Australia
${ }^{2}$ Key Laboratory of Coal Science and Technology, Taiyuan University of Technology, Ministry of Education and Shanxi Province, Taiyuan, 030024, P.R China

${ }^{3}$ Fuels and Energy Technology Institute, Curtin University of Technology, GPO Box U1987, Perth, WA 6845, Australia
\end{abstract}

\begin{abstract}
There are a large number of factors affecting the gasification reactivity of chars, including physical structure (e.g. surface area and pore structure), catalytically-active mineral matter, and chemical structure which includes the extent of crystallinity of the carbonaceous matrix and also the nature of the functional groups that comprise the char structure. This work focuses on the latter, using Raman spectroscopy to investigate the relationships between intrinsic reactivity and char chemical structure. An Australian bituminous coal char and a Chinese lignite char were characterised in terms of their intrinsic reactivities with $\mathrm{CO}_{2}$ and $\mathrm{H}_{2} \mathrm{O}$ (separately), under conditions where chemical processes control the observed reaction rates (Regime I). Unreacted and partially-reacted chars were characterised using Raman spectroscopy and gas adsorption for determination of chemical structure indicators and surface area respectively. Raman spectra suggested that the ratio of small to large aromatic rings decreased with increasing carbon conversion, and for the bituminous coal char, this seemed to be linked to the reactivity behaviour of chars made from the bituminous coal. The intrinsic reactivity of chars made from the lignite seemed to have a less significant correlation with Raman features, possibly due to the relative influence of catalytic activity of inorganic species.
\end{abstract}

KEY WORDS: Gasification reactivity, Raman spectroscopy, Chemical structure

\footnotetext{
*Corresponding author: E-mail address: Daniel.Roberts@csiro.au
} 


\section{Introduction}

Coal gasification involves two primary steps: pyrolysis of coal (devolatilisation) to produce char, tar and gases, and subsequent gasification of the residual char. As char gasification is the slowest step in the coal conversion process, char reactivity is an important aspect of understanding coal behaviour under gasification conditions. Char structure is a key property affecting its reactivity behaviour, and it is known to change with carbon conversion. Therefore, a good understanding of physical and chemical char structure, and how they affect char reactivity behaviour, is important.

Chemical structures of char can be characterised with the help of advanced techniques including X-ray diffraction (XRD), Fourier transform infrared spectroscopy (FTIR), and Raman spectroscopy. X-Ray diffraction techniques have been used to determine the extent of crystalline features in chars, and to relate them to reactivity, and it is clear that there is a strong negative correlation between char crystallinity and reactivity [1-2]. Recently, Raman spectroscopy was used to analyse coal char structure, and some correlations were made with aspects of char reactivity [3-10]. The evolution of char structure during gasification has been shown to be affected by thermal annealing [11], the preferential consumption of smaller aromatic structures [12], the changes in the structure of the unreacted portions of the char with the occurrence of gasification reaction [13], and the interaction of char with volatiles or the transformation of smaller aromatic structures to larger aromatic components [14-15]. Many of these changes in chemical structure are expected to affect the reactivity of the char.

The 'intrinsic' reactivity of a char is characterised by the reaction rate determined under conditions where chemical processes alone control reaction rates. Data are usually normalised to some measure of the total surface area of the char, so that they reflect the inherent nature of the carbon surface (including any influences of mineral matter and other impurities). Studies of intrinsic char reactivity have revealed information regarding the mechanisms of char-gas reactions, e.g. [16], aspects of kinetic descriptions of char gasification systems [17] and how these are affected by product gas concentrations [18] and increased partial pressures of reactants $[19,20]$. Previous studies have begun to investigate how individual reactions, and reactants, interact at a reacting char surface [21]. These factors an important consideration when applying such fundamental kinetic information to industrially-relevant systems where reactant (and product) gas compositions in the vicinity of reacting char particles vary widely.

Although char structure-reactivity relationships are widely researched, there are few data allowing isolation of the relationship between intrinsic reactivity and char chemical structure. This initial study uses Raman spectroscopy to characterise the features of the chemical structures of two coal chars, and relates these to the low-temperature, intrinsic reactivity behaviour of these chars with $\mathrm{CO}_{2}$ and $\mathrm{H}_{2} \mathrm{O}$. 


\section{Experimental}

\subsection{Sample Preparation}

Two coal samples were used in this work: a lignite from China (Coal C) and a bituminous coal from Australia (Coal A), both crushed and sieved to a particle size of $-1.0+0.6 \mathrm{~mm}$. To prepare reference chars, coal samples were loaded into ceramic boats into a horizontal tube furnace (HTF) purged with $\mathrm{N}_{2}$ at $1.5 \mathrm{~L} / \mathrm{min}$. The sample was heated from room temperature to the desired temperature at a heating rate of $6^{\circ} \mathrm{C} / \mathrm{min}$ and held for $3 \mathrm{~h}$. Chars were produced at two temperatures in this work: 900 and $1100^{\circ} \mathrm{C}$. The proximate and ultimate analyses results of the coal and char samples are presented in Table 1, and the ash analyses of raw coals in Table 2.

Table 1. Proximate and ultimate analyses of samples

\begin{tabular}{ccccccccc}
\hline \multirow{2}{*}{ Sample } & \multicolumn{3}{c}{ Proximate analysis, wt $/ \%$} & \multicolumn{3}{c}{ Ultimate analysis, wt/\%(daf) } \\
\cline { 2 - 9 } & $\mathrm{M}_{\mathrm{ad}}$ & $\mathrm{A}_{\mathrm{d}}$ & $\mathrm{V}_{\mathrm{daf}}$ & $\mathrm{FC}_{\mathrm{ad}}$ & $\mathrm{C}$ & $\mathrm{H}$ & $\mathrm{N}$ & $\mathrm{S}$ \\
\hline Coal C & 17.6 & 10.1 & 47.2 & 39.1 & 68.5 & 4.6 & 1.0 & 2.6 \\
HTF900-CoalC & 3.4 & 15.8 & 3.7 & 78.3 & 97.4 & 0.9 & 1.6 & 2.2 \\
HTF1100-CoalC & 2.7 & 15.6 & 1.5 & 80.9 & 99.7 & 0.7 & 1.5 & 2.2 \\
\hline Coal A & 3.0 & 11.2 & 39.4 & 52.2 & 82.1 & 5.5 & 1.8 & 1.0 \\
HTF900-CoalA & 2.6 & 23.3 & 1.9 & 73.3 & 97.6 & 1.0 & 1.9 & 1.1 \\
HTF1100-CoalA & 0.4 & 21.7 & $<0.1$ & 78.0 & 99.7 & 0.7 & 1.1 & 1.1 \\
\hline
\end{tabular}

Table 2. Ash analyses of coal samples

\begin{tabular}{ccccccccccc}
\hline \multirow{2}{*}{ Sample } & \multicolumn{8}{c}{ Ash composition (wt\%) } \\
\cline { 2 - 11 } & $\mathrm{SiO}_{2}$ & $\mathrm{Al}_{2} \mathrm{O}_{3}$ & $\mathrm{Fe}_{2} \mathrm{O}_{3}$ & $\mathrm{CaO}$ & $\mathrm{MgO}$ & $\mathrm{TiO}_{2}$ & $\mathrm{SO}_{3}$ & $\mathrm{~K}_{2} \mathrm{O}$ & $\mathrm{Na}_{2} \mathrm{O}$ & $\mathrm{P}_{2} \mathrm{O}_{5}$ \\
\hline Coal C & 30.2 & 14.5 & 9.7 & 18.2 & 4.9 & 1.2 & 18.6 & 0.6 & 0.9 & 0.63 \\
Coal A & 47.9 & 26.5 & 7.49 & 7.86 & 0.59 & 1.91 & 6.08 & 0.33 & 0.09 & 1.29 \\
\hline
\end{tabular}

\subsection{Reactivity Measurements}

Reactivity measurements were made using a laboratory-scale fixed bed reactor, which has been described previously [22]. It is a quartz reactor, which suspends approximately $1.0-1.5 \mathrm{~g}$ of char on a quartz frit, into which a thermocouple is inserted to measure the temperature of the sample bed. Reactant gas is passed through the sample, and measurements of gas concentration and flow rates are used to determine reaction rates. 
The specific reaction rate $\left(\rho_{\mathrm{s}}\right)$ is the as-measured reaction rate, and was calculated using the expression in Equation 1:

$\rho_{s}=-\frac{1}{W} \frac{d W}{d t} g \cdot g^{-1} \cdot s^{-1}$

where, $W$ is the sample mass (daf) remaining at reaction time $t$.

At pre-determined levels of conversion $(1 \%, 10 \%$ and $20 \%)$ the sample was cooled and rate measurements made as a function of temperature. The rate of cooling was sufficiently rapid to provide a series of rate vs temperature data, without any significant change in conversion. These data were used to determine activation energies for the reaction system, which in turn were used to normalise the reaction rate to a common temperature.

\subsection{Char characterisation}

FT-IR/Raman spectra of chars were recorded with a Perkin-Elmer Spectrum GX FTIR/Raman spectrometer $[12-15,23]$. The char sample was firstly diluted and ground with IR grade $\mathrm{KBr}$ to a concentration of $0.5 \mathrm{wt} \%$. This diluted sample was then used to record the Raman spectrum. An InGaAs detector constantly cooled in liquid nitrogen was used to collect Raman scattering using a back scattering configuration. The excitation Nd:YAG laser wavelength was $1064 \mathrm{~nm}$, the laser power was $150 \mathrm{~mW}$ and the spectral resolution was $4 \mathrm{~cm}^{-1}$.

The recorded Raman spectra in the range between 800 and $1800 \mathrm{~cm}^{-1}$ were curve-fitted using the GRAMS/32 AI software with 10 Gaussian bands (Table 3) representing the typical structures to be found in chars. A detailed methodology on the band assignment has been reported previously [23]. One example of spectral deconvolution is given in Figure 1. Of the 10 bands, the assignment of the six main bands $\left(G, G_{R}, V_{L}, V_{R}, D\right.$ and $\left.S\right)$ will be summarised here briefly $[12,14]$.

The $\mathrm{G}$ band at $1590 \mathrm{~cm}^{-1}$ mainly represents aromatic ring quadrant breathing, and the contribution of graphite $\mathrm{E}_{2 \mathrm{~g}}^{2}$ vibration is minimal because of the lack of true graphite structures in such low temperature chars $[12,14]$. The $\mathrm{D}\left(1300 \mathrm{~cm}^{-1}\right)$ band represents defect structures in the highly ordered carbonaceous materials and, more importantly, aromatics with 6 or more fused rings. The overlap between the $\mathrm{D}$ and $\mathrm{G}$ bands has been deconvoluted into three bands: $\mathrm{G}_{\mathrm{R}}\left(1540 \mathrm{~cm}^{-1}\right), \mathrm{V}_{\mathrm{L}}\left(1465 \mathrm{~cm}^{-1}\right)$ and $\mathrm{V}_{\mathrm{R}}\left(1380 \mathrm{~cm}^{-1}\right)$. These bands represent typical structures in amorphous carbon (especially smaller aromatic ring systems) as well as the semicircle breathing of aromatic rings. The $\mathrm{S}\left(1185 \mathrm{~cm}^{-1}\right)$ band mainly represents Caromatic-Calkyl, aromatic (aliphatic) ethers, $\mathrm{C}-\mathrm{C}$ on hydroaromatic rings, hexagonal diamond carbon $\mathrm{sp}^{3}$ and $\mathrm{C}-\mathrm{H}$ on aromatic rings.

Surface areas of the chars were measured using adsorption of $\mathrm{CO}_{2}$ at $273 \mathrm{~K}$ and data analysis using the Dubinin-Radushkevic (DR) method. 
Table 3.Summary of Peak/band assignment [2]

\begin{tabular}{|c|c|c|c|}
\hline $\begin{array}{l}\text { Band } \\
\text { name }\end{array}$ & Band position, $\mathrm{cm}^{-1}$ & Description & Bond type \\
\hline$\overline{\mathrm{G}_{\mathrm{L}}}$ & 1700 & Carbonyl group $\mathrm{C}=\mathrm{O}$ & $\overline{\mathrm{sp}^{2}}$ \\
\hline G & 1590 & Graphite $E_{2 g}^{2}$; aromatic ring quadrant breathing; alkene $\mathrm{C}=\mathrm{C}$ & $\mathrm{sp}^{2}$ \\
\hline $\mathrm{G}_{\mathrm{R}}$ & 1540 & Aromatics with 3-5 rings; amorphous carbon structures & $\mathrm{sp}^{2}$ \\
\hline $\mathrm{V}_{\mathrm{L}}$ & 1465 & $\begin{array}{l}\text { Methylene or methyl; semi-circle breathing of aromatic rings; } \\
\text { amorphous carbon structures }\end{array}$ & $\mathrm{sp}^{2}, \mathrm{sp}^{3}$ \\
\hline$V_{R}$ & 1380 & $\begin{array}{l}\text { Methyl group; semi-circle breathing of aromatic rings; } \\
\text { amorphous carbon structures }\end{array}$ & $\mathrm{sp}^{2}, \mathrm{sp}^{3}$ \\
\hline $\mathrm{D}$ & 1300 & $\begin{array}{l}\mathrm{D} \text { band on highly ordered carbonaceous materials; } \mathrm{C}-\mathrm{C} \\
\text { between aromatic rings and aromatics with not less than } 6 \text { rings }\end{array}$ & $\mathrm{sp}^{2}$ \\
\hline $\mathrm{S}_{\mathrm{L}}$ & 1230 & Aryl-alkyl ether; para-aromatics & $\mathrm{sp}^{2}, \mathrm{sp}^{3}$ \\
\hline $\mathrm{S}$ & 1185 & $\begin{array}{l}\text { Caromatic-Calkyl; aromatic (aliphatic) ethers; } \mathrm{C}-\mathrm{C} \text { on } \\
\text { hydroaromatic rings; hexagonal diamond carbon sp3; C-H on } \\
\text { aromatic rings }\end{array}$ & $\mathrm{sp}^{2}, \mathrm{sp}^{3}$ \\
\hline $\mathrm{S}_{\mathrm{R}}$ & 1060 & $\mathrm{C}-\mathrm{H}$ on aromatic rings; benzene (ortho-di-substituted) ring & $\mathrm{sp}^{2}$ \\
\hline $\mathrm{R}$ & $960-800$ & $\mathrm{C}-\mathrm{C}$ on alkanes and cyclic alkanes; $\mathrm{C}-\mathrm{H}$ on aromatic rings & $\mathrm{sp}^{2}, \mathrm{sp}^{3}$ \\
\hline
\end{tabular}

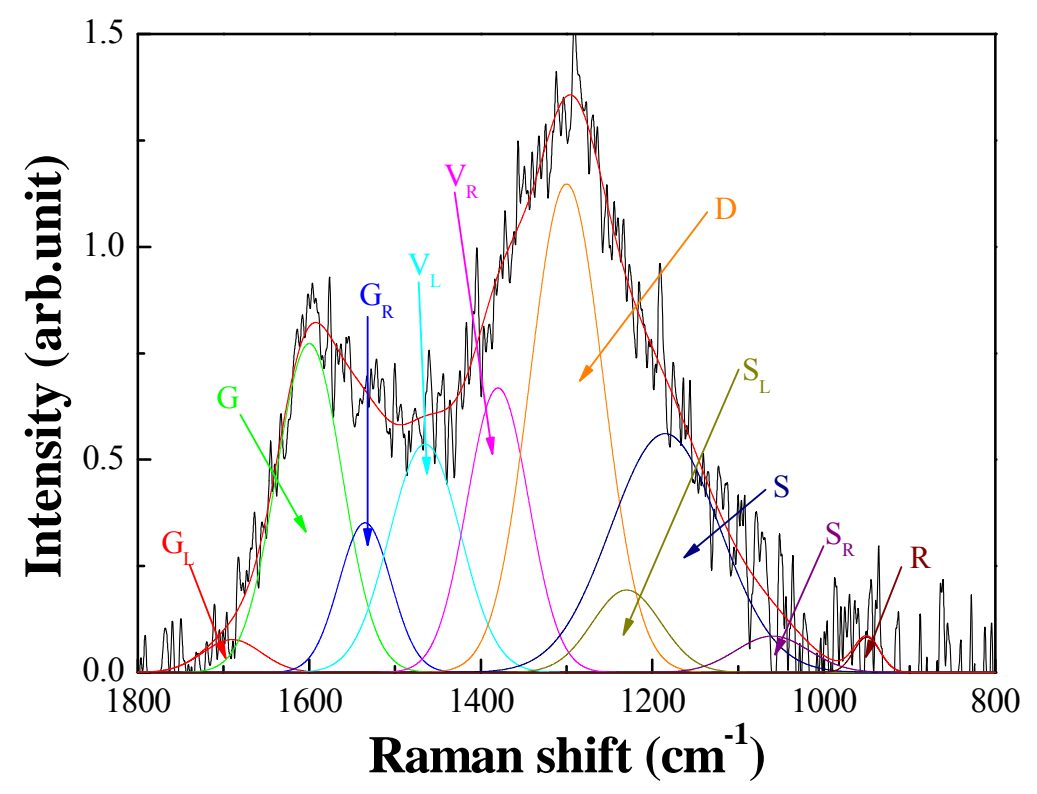

Figure 1. Curve-fitting of a Raman spectrum of the HTF 900-Coal A char from reaction in steam to a conversion of $1 \%$. 


\section{Results and discussion}

\subsection{Char Reactivity}

Figure 2 shows specific reaction rate as a function of carbon conversion during reaction with $\mathrm{CO}_{2}$ (normalised to $900^{\circ} \mathrm{C}$ ) and steam (normalised to $850^{\circ} \mathrm{C}$ ). From Figure 2, we can see that specific rates with $\mathrm{CO}_{2}$ and $\mathrm{H}_{2} \mathrm{O}$ increase gradually with increasing carbon conversion for all chars. The specific reaction rates of chars produced from coal $\mathrm{C}$ are higher than those chars from coal $\mathrm{A}$, for both $\mathrm{CO}_{2}$ and $\mathrm{H}_{2} \mathrm{O}$ gasification, consistent with what one might expect based on the relative ranks of the two parent coals. Chars from coal $\mathrm{C}$ were more than 30 times more reactive than those from coal $\mathrm{A}$ in $\mathrm{CO}_{2}$ whereas the difference was a factor of 5 for $\mathrm{H}_{2} \mathrm{O}$ gasification.

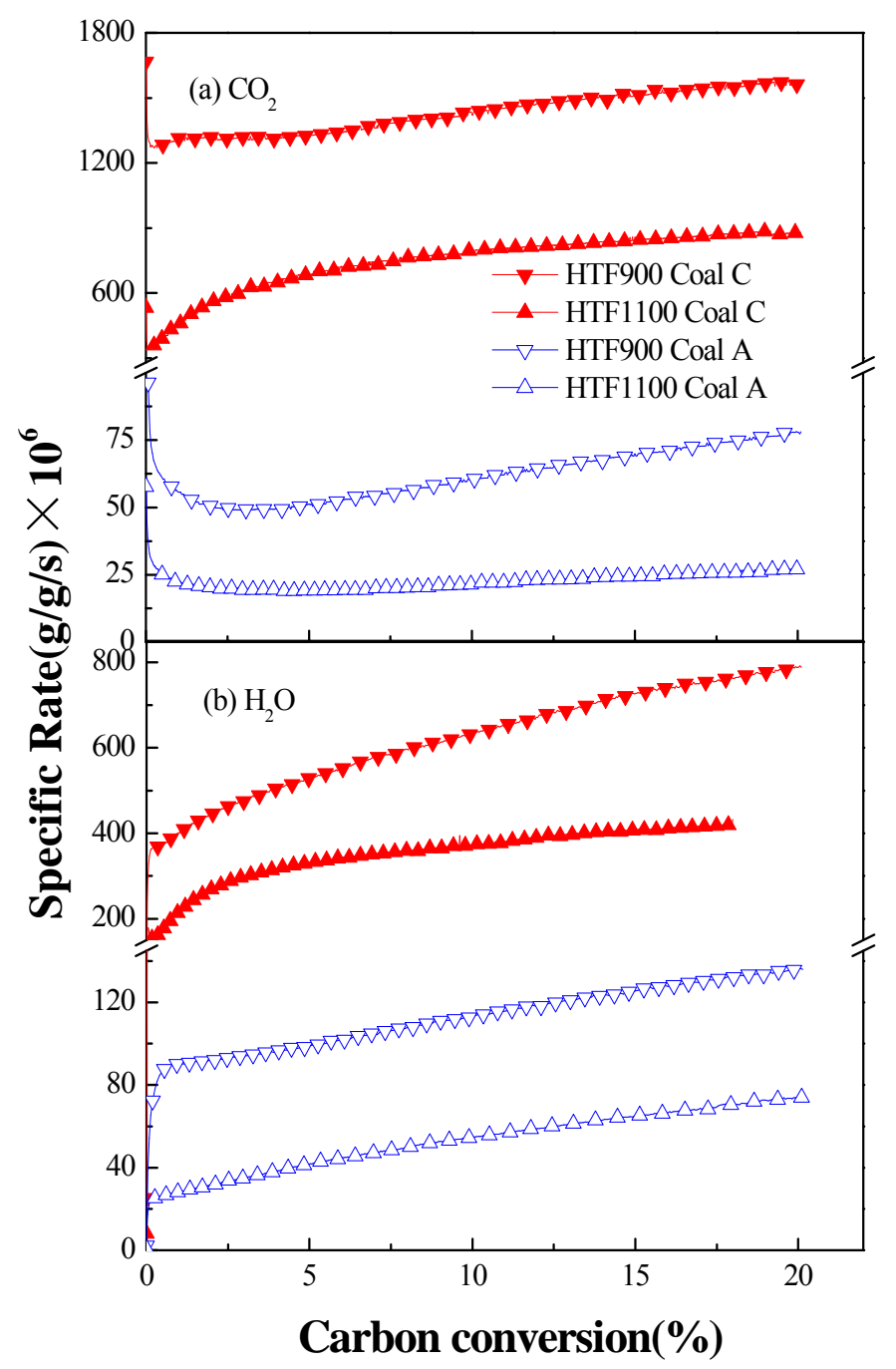

Figure 2. Specific reaction rates as a function of carbon conversion during reaction with (a) $\mathrm{CO}_{2}$ at $900^{\circ} \mathrm{C}$, and (b) steam at $850^{\circ} \mathrm{C}$ (note dual scales used on the ordinate). 
Surface areas of chars at different levels of conversion are presented in Figure 3. There exist very different trends of surface area development with increasing carbon conversions for the chars made from the two different coals. For the chars made from coal $\mathrm{C}$, we can see that surface area does not change significantly with increasing carbon conversion, whereas surface areas of chars from coal A generally increase with increasing carbon conversion. There is a particularly rapid change in surface areas during the early stages of reaction; this is most likely related to the consumption of reactive material leading to a rapid development and opening of some of the previously inaccessible surface.

Chars produced at $900^{\circ} \mathrm{C}$ have higher surface areas than those produced at $1100^{\circ} \mathrm{C}$. This is also consistent with previous work in this area, which suggests that this is related to the effect of temperature on physical and chemical changes in coal structure during heating.

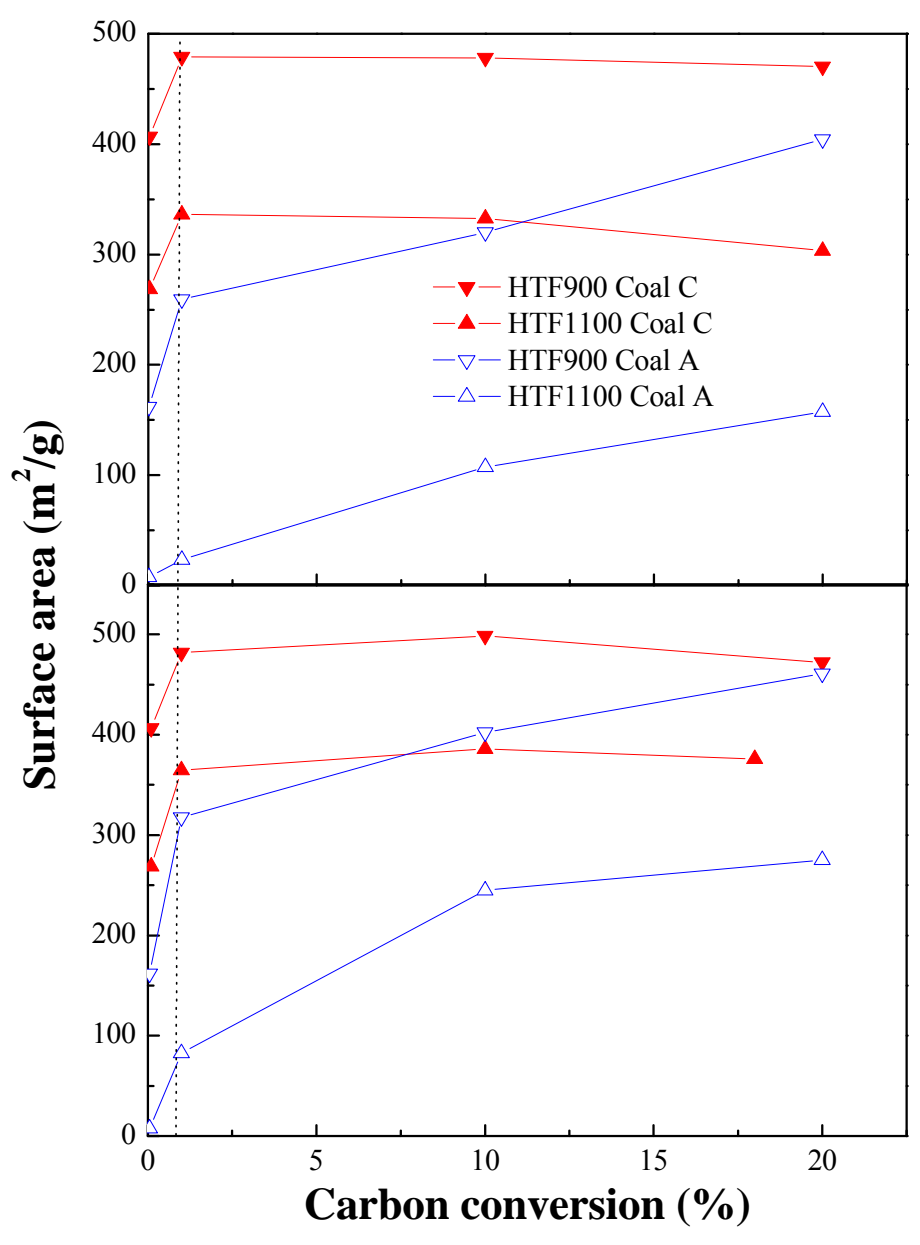

Figure 3. $\mathrm{CO}_{2}$ DR surface areas as a function of carbon conversion during reaction with $\mathrm{CO}_{2}$ and $\mathrm{H}_{2} \mathrm{O}$.

The use of intrinsic reactivity accounts for much of the surface area effects associated with the specific or 'apparent' rate data, and better reflects the inherent nature of the char surface (and any influences of mineral matter and other impurities). The intrinsic reaction rates of chars as a function of carbon conversion are shown in Figure 4 . Following the initial $\sim 1 \%$ of 
conversion (where we have seen that surface areas are changing significantly) we can see that, relative to specific rates, intrinsic rates are less affected by conversion. i.e the reaction produces more surface area which has a similar 'intrinsic' reactivity characteristics to the material removed by gasification. This is consistent with our understanding that changing surface area during reaction is an important contributor, but not the complete reason for the observed rate variations with conversion. The fact that the 'intrinsic' reactivity still demonstrates some variation during conversion also suggests that there are other aspects that are important to consider. This is particularly the case for Coal C.

The intrinsic reactivity of chars devolatilised at $900^{\circ} \mathrm{C}$ is higher than that of those made at $1100^{\circ} \mathrm{C}$. This is consistent with our understanding of the effects of temperature on annealing and its impacts on reactivity [24]. Chars from Coal $\mathrm{C}$ have a higher intrinsic reaction rate than those from coal A, consistent with the specific rate data, although the magnitude of this difference is less on an intrinsic basis. This reinforces the notion that there are a range of rank-related factors (of which surface area is one) that contribute to the high relative reactivity of low-rank coals.

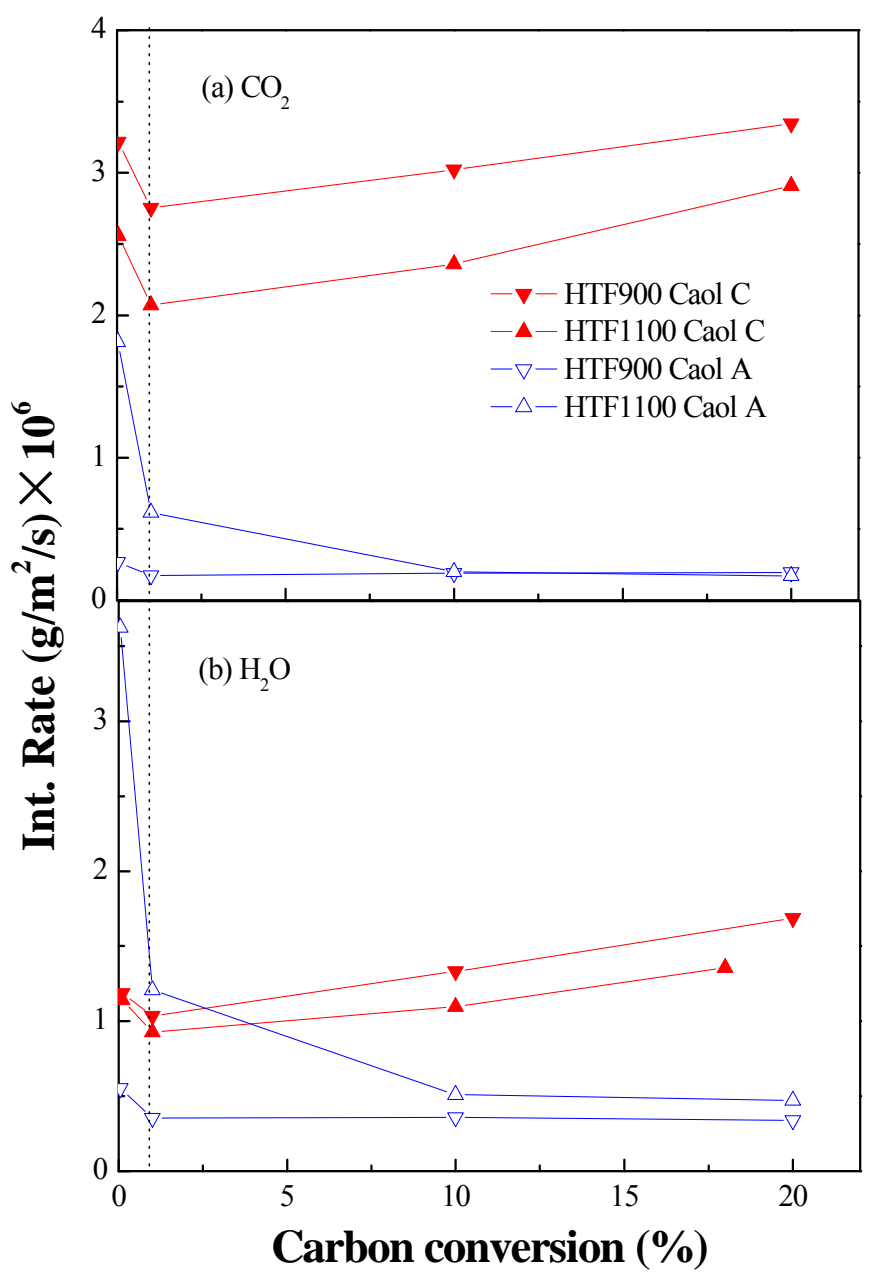

Figure 4. Intrinsic reaction rates as a function of carbon conversion during reaction with (a) $\mathrm{CO}_{2}$ at $900^{\circ} \mathrm{C}$ and (b) $\mathrm{H}_{2} \mathrm{O}$ at $850^{\circ} \mathrm{C}$. 


\subsection{Chemical structures of chars by the Raman spectroscopy}

The chemical structures of these chars were characterised using Raman spectroscopy to investigate possible links between intrinsic reactivity and char chemical structure. The total Raman peak areas between $800-1800 \mathrm{~cm}^{-1}$ for chars obtained from the gasification with $\mathrm{CO}_{2}$ or $\mathrm{H}_{2} \mathrm{O}$ are shown in Figure 5. It shows that the total Raman peak area from measurements of chars reacted with $\mathrm{CO}_{2}$ and $\mathrm{H}_{2} \mathrm{O}$ increases with increasing carbon conversion, and that the data from $\mathrm{CO}_{2}$ reaction are approximately linear, whereas the results from the $\mathrm{H}_{2} \mathrm{O}$ reacted chars are not.

Previous work [23, 25] suggests that the total Raman intensity is affected by the intrinsic Raman scattering ability, light absorptivity of the char and the presence of O-containing groups in the char. The influence of O-containing species may be the difference between the linearity of the data for $\mathrm{CO}_{2}$-reacted chars and $\mathrm{H}_{2} \mathrm{O}$ reacted chars, as steam gasification is likely to produce a more complex range of surface intermediates [26, 27]. Of more interest, however is the data for specific features of these Raman spectra, which are discussed in more detail below.

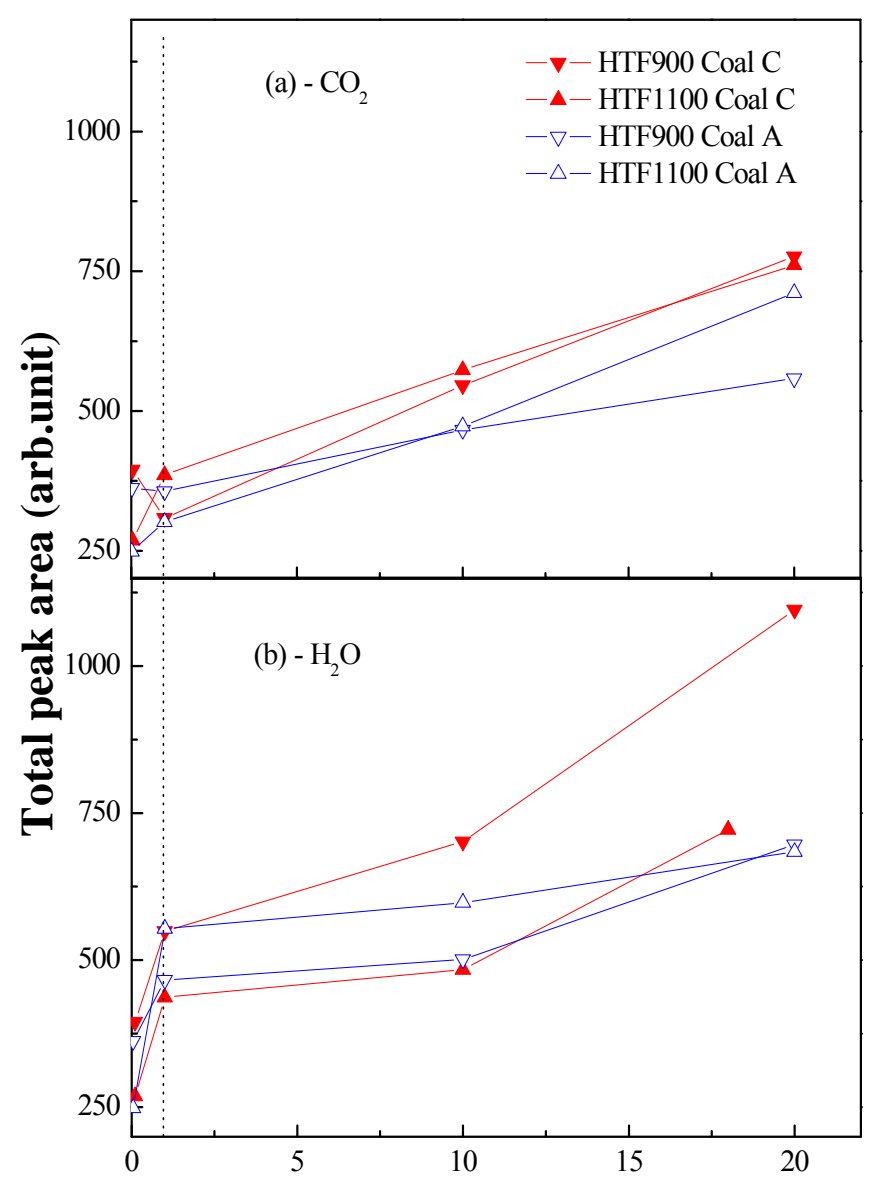

Carbon conversion (\%)

Figure 5. Total areas of Raman peak $\left(\mathrm{I}_{\text {Total }}\right)$ as a function of carbon conversion following reaction in (a) $\mathrm{CO}_{2}$ at $900^{\circ} \mathrm{C}$ and (b) $\mathrm{H}_{2} \mathrm{O}$ at $850^{\circ} \mathrm{C}$. 
The Raman spectra were deconvoluted into 10 Gaussian bands (see Table 3). The band area ratio $\mathrm{I}_{\mathrm{G}} / \mathrm{I}_{\text {Total }}$ is shown in Figure 6; as described above, the $\mathrm{G}$ band at $1590 \mathrm{~cm}^{-1}$ mainly represents the aromatic ring systems. The $\mathrm{I}_{\mathrm{G}} / \mathrm{I}_{\text {Total }}$ ratios are almost constant with increasing carbon conversion, notwithstanding the changes that occur between $0-1 \%$ carbon conversion. Many aspects of char chemical and physical structure are changing during these initial stages of reaction; more work is required to fully understand the implications of the early-conversion data in Figure 6. The data from higher levels of conversion, however, suggest that the fundamental carbon matrix of chars is not changed significantly during reaction under these conditions.

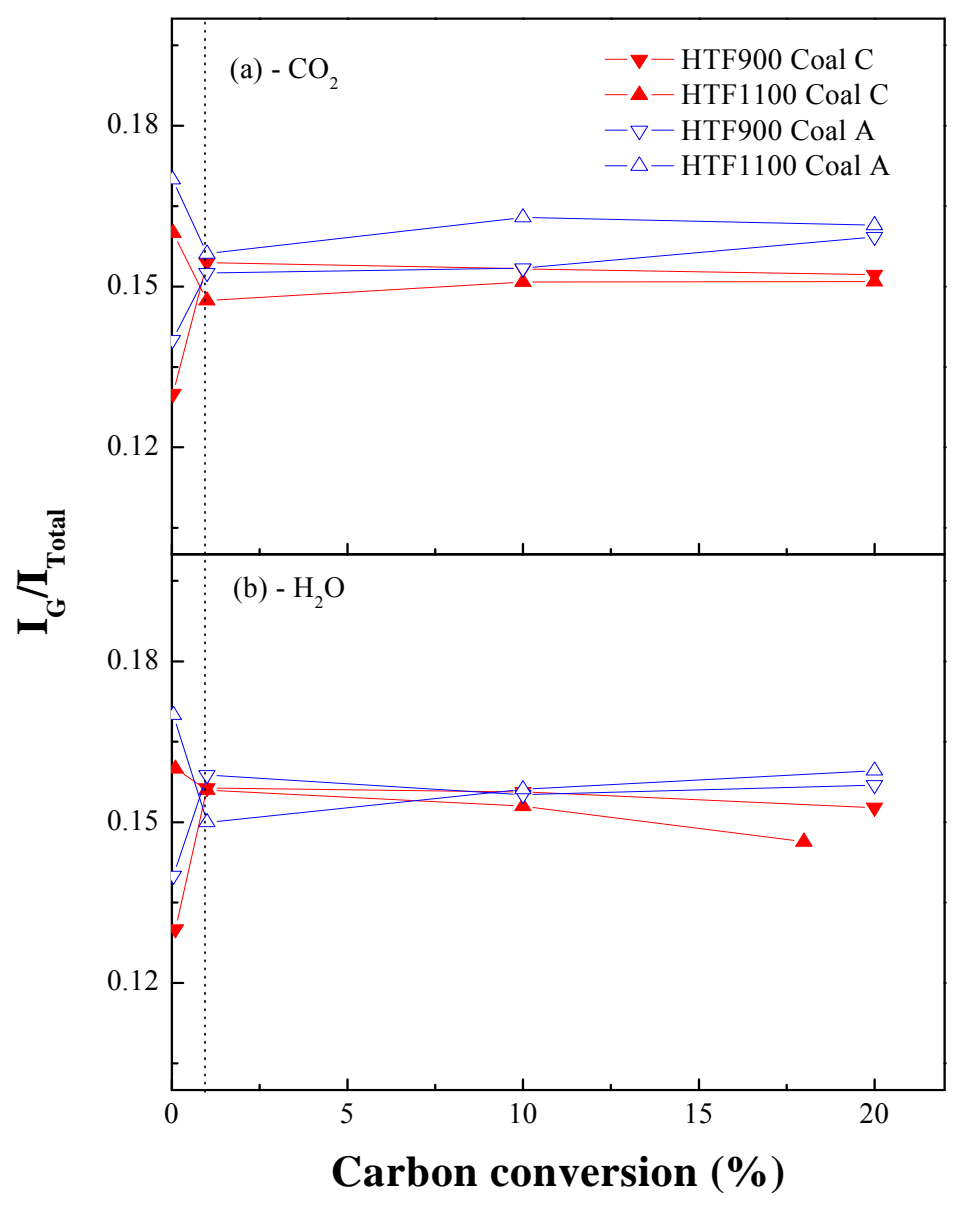

Figure 6. Ratio of $\mathrm{I}_{\mathrm{G}} / \mathrm{I}_{\text {Total }}$ as a function of carbon conversion following reaction in (a) $\mathrm{CO}_{2}$ at $900^{\circ} \mathrm{C}$ and (b) $\mathrm{H}_{2} \mathrm{O}$ at $850^{\circ} \mathrm{C}$.

The band area ratio $\mathrm{I}_{(\mathrm{GR}+\mathrm{VL}+\mathrm{VR})} / \mathrm{I}_{\mathrm{D}}$ are shown in Figure 7 , which is used here as a broad indication of the ratios of small and large ( $\geq 6$ rings) aromatic ring systems [12-14, 23]. As shown in Figure 7, following an initial increase in the very early stages of reaction, the $\mathrm{I}_{(\mathrm{GR}+\mathrm{VL}+\mathrm{VR})} / \mathrm{I}_{\mathrm{D}}$ band area ratio decreases with increasing carbon conversion for all samples. This suggests that the smaller aromatic ring structures are preferentially consumed and/or converted into larger ones during the gasification process, in broad agreement with the published studies [10, 12-15]. Given the heat treatment histories of these samples, the preferential consumption of smaller ring structures is the more likely explanation. Most of 
this effect is noticed in the first $10 \%$ of conversion, after which it seems that these smaller aromatic structures have largely been preferentially removed by reaction. .

It is also worthwhile to note that the $\mathrm{I}_{(\mathrm{GR}+\mathrm{VL}+\mathrm{VR})} / \mathrm{I}_{\mathrm{D}}$ band area ratios from chars at $900^{\circ} \mathrm{C}$ are generally (slightly) larger than those from chars at $1100^{\circ} \mathrm{C}$, which is consistent with our understanding of the effect of increased temperature on annealing processes and, consequently, the size of chemical features.

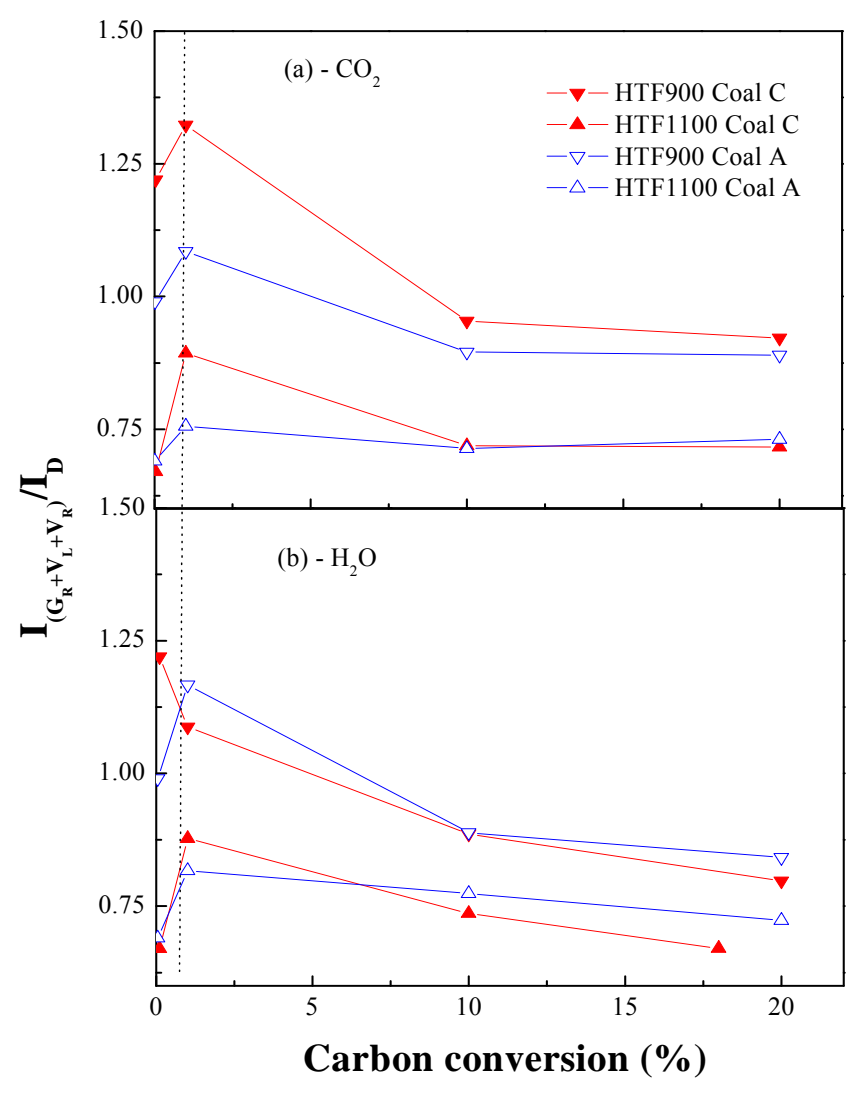

Figure 7. Ratio of $\mathrm{I}_{(\mathrm{GR}+\mathrm{VL}+\mathrm{VR})} / \mathrm{I}_{\mathrm{D}}$ as a function of carbon conversion following reaction in (a) $\mathrm{CO}_{2}$ at $900^{\circ} \mathrm{C}$ and $\left(\right.$ b) $\mathrm{H}_{2} \mathrm{O}$ at $850^{\circ} \mathrm{C}$.

\subsection{Relationships between chemical structure and intrinsic reactivity}

Combined with the data of intrinsic reactivity from Figure 4, we can see that there is a relationship between intrinsic reactivity and $\mathrm{I}_{(\mathrm{GR}+\mathrm{VL}+\mathrm{VR})} / \mathrm{I}_{\mathrm{D}}$ band area ratios for the chars from Coal A. These results suggest that the intrinsic reactivity of char is related to the $\mathrm{I}_{(\mathrm{GR}+\mathrm{VL}+\mathrm{VR})} / \mathrm{I}_{\mathrm{D}}$ band area ratios of the chars, as intrinsic reactivity and $\mathrm{I}_{(\mathrm{GR}+\mathrm{VL}+\mathrm{VR})} / \mathrm{I}_{\mathrm{D}}$ band area ratios both decrease during reaction. It is inferred that the smaller aromatic ring structures are an important factor affecting intrinsic reactivity: when these smaller aromatic structures have largely been reacted, the intrinsic reactivity is almost constant with increasing carbon conversion. 
These links are not as clear for the lignite chars from Coal C. For those chars, intrinsic reactivity increases with increasing conversion, whereas the $\mathrm{I}_{(\mathrm{GR}+\mathrm{VL}+\mathrm{VR})} / \mathrm{I}_{\mathrm{D}}$ band area ratios do not. This may be related to the relative impact of carbon chemical features and the possible catalytic activity of inherent mineral matter on the chars from the lignitic Coal C. As indicated in Table 2, alkali metals, alkaline earth metals (especially, calcium, magnesium and potassium) and iron are present with higher concentrations in coal $\mathrm{C}$ than in Coal $\mathrm{A}$. It is generally understood that the reactivity of chars from lower rank coals is more likely to be affected by catalytic processes associated with organically bound alkali species. After accounting for the typically large surface areas of these chars, these catalytic aspects therefore have a larger role in determining the reactivity of the surface [28]. The proportion (and possibly the availability) of the mineral matter species in the chars also increases with increasing carbon conversion, potentially increasing the role of catalytic processes.

\section{Conclusions}

Measurements of the reactivity of a lignite char and a bituminous coal char with $\mathrm{CO}_{2}$ and $\mathrm{H}_{2} \mathrm{O}$ have been made, with the results discussed in the context of physical structure (surface areas) and chemical structure, as determined using Raman spectroscopy. Two Raman features were used to interpret relative coal char reactivity: the proportion of aromatic structures, and the ratio of small to large aromatic rings. Whilst the proportion of all aromatic structures does not seem to be related to intrinsic reactivity, the ratio of small to large aromatic rings decreases with increasing carbon conversion for the bituminous char, in a similar manner as the intrinsic reactivity of these chars. These results suggest that the proportion of smaller aromatic ring structures is a factor affecting the intrinsic reactivity of bituminous chars. This is not as clear for the chars from the lignite, suggesting that the catalytic activity of the mineral matter in the lignite char is a more significant influence on char reactivity than chemical features of the char structure.

Acknowledgements We wish to thank Tingting Li of Curtin University of Technology for her help in carrying out the Raman measurements in this work.

\section{References}

[1] O O. Sonibare, T Haeger, S and F. Foley. Structural characterization of Nigerian coals by X-ray diffraction, Raman and FTIR spectroscopy, Energy 35 5347-5353 (2010).

[2] L Lu, V Sahajwalla, C Kong and D Harris. Quantitative X-ray diffraction analysis and its application to various coals, Carbon 39 1821-1833 (2001).

[3] C D Sheng. Char structure characterized by Raman spectroscopy and its correlation with combustion reactivity, Fuel 86 2316-2324 (2007).

[4] X L Zhu, C D Sheng. Evolution of the char structure of Lignite under Heat Treatment and its influences on combustion reactivity, Energy \& Fuels 24 152-159 (2010). 
[5] A Zaida, E Bar-Ziv, L R. Radovic and Y J Lee. Further development of Raman microprobe spectroscopy for characterization of char reactivity, Proceedings of the combustion institute 31 1881-1887 (2007).

[6] E Bar-Zia, A Zaida, P Salatino and O Senneca. Diagnostics of carbon gasification by Raman microprobe spectroscopy, Proceedings of the combustion institute 28 2369-2374 (2000).

[7] Y Sekine, K Ishikawa, E Kikuchi and M Matsukata. New evaluation method of carbonaceous structure on coal steam gasification, Energy \& Fuels 19 326-327 (2005).

[8] Y Sekine, K Ishikawa, E Kikuchi, M Matsukata and A Akimoto. Reactivity and structural change of coal char during steam gasification, Fuel 85 122-126 (2006).

[9] H L Tay and C Z Li. Changes in char reactivity and structure during the gasification of a Victorian brown coal: Comparison between gasification in $\mathrm{O}_{2}$ and $\mathrm{CO}_{2}$, Fuel Processing Technology 91 800-804 (2010).

[10] C Z Li. Some recent advances in the understanding of the pyrolysis and gasification behaviour of Victorian brown coal, Fuel 86 1664-1683 (2007).

[11] B Feng, S K Bhatia and J C Barry. Structural ordering of coal char during heat treatment and its impact on reactivity, Carbon 40 481-496 (2002).

[12] X Guo, H L Tay, S Zhang and C Z Li. Changes in char structure during the gasification of a Victorian brown coal in steam and oxygen at $800^{\circ} \mathrm{C}$, Energy \& Fuels $224034-4038$ (2008).

[13] H L Tay, S Kajitani, S Zhang and C Z Li. Effects of gasifying agent on the evolution of char structure during the gasification of Victorian brown coal, Fuel doi:

10.1016/j.fuel.2011.02.044 (2011).

[14] S Zhang, Z H Min, H L Tay, M Asadullah and C Z Li. Effects of volatile-char interactions on the evolution of char structure during the gasification of Victorian brown coal in steam, Fuel 90 1529- 1535 (2011).

[15] X J Li, H W Wu, J Hayashi and C Z Li. Volatilisation and catalytic effects of alkali and alkaline earth metallic species during the pyrolysis and gasfication of Victorian brown coal. Part VI. Further invertigation into the effects of volatile-char interactions, Fuel 83 1273-1279 (2004).

[16] P L Walker, Jr., F Rusinko, Jr. and L G Austin. Gas Reactions of Carbon. In: D D Eley, P W Selwood and P B Weisz (Eds.) Advances in Catalysis, Volume 11. Academic Press, NY and London (1959).

[17] N M Laurendeau. Heterogeneous Kinetics of Coal Char Gasification and Combustion, Progress in Energy and Combustion Science 4 221-270 (1978). 
[18] D A Aderibigbe and J Szekely. Studies in coke reactivity: Part 1 reaction of conventionally produced coke with $\mathrm{CO}-\mathrm{CO}_{2}$ mixtures over temperature range $850-1000^{\circ} \mathrm{C}$, Ironmaking and Steelmaking 8(1) 11-19 (1981).

[19] H-J Mühlen, K H van Heek and H Jüntgen. Kinetic studies of steam gasification of char in the presence of $\mathrm{H}_{2}, \mathrm{CO}_{2}$ and $\mathrm{CO}$, Fuel 64 944-949 (1985).

[20] D G Roberts and D J Harris. A Kinetic Analysis of Coal Char Gasification Reactions at High Pressures, Energy and Fuels 20 2314-2320 (2006).

[21]D G Roberts and D J Harris. Char Gasification in Mixtures of $\mathrm{CO}_{2}$ and $\mathrm{H}_{2} \mathrm{O}$ : Competition and Inhibition, Fuel 86 2672-2678 (2007).

[22] D J Harris and I W Smith. Intrinsic reactivity of petroleum coke and brown coal char to carbon dioxide, steam and oxygen, Twenty-third Symposium (International) on Combustion 1185-1190 (1990).

[23] X J Li, J Hayashi and C Z Li. FT-Raman spectroscopic study of the evolution of char structure during the pyrolysis of a Victorian brown coal, Fuel 85 1700-1707 (2006).

[24] M L Chan, J M Jones, M Pourkashanian and A Williams. The oxidative reactivity of coal chars in relation to their structure, Fuel 78 1539-1552 (1999).

[25] L A Leites and S S Bukalov. Raman intensity and conjugation with participation of ordinary $\sigma$-bonds, Journal of Raman Spectroscopy 32 413-424 (2001).

[26] J F Espinal, F Mondragon and T N Truong. Thermodynamic evaluation of steam gasification mechanisms of carbonaceous materials, Carbon 47 3010-3018 (2009).

[27] X J Li and C Z Li. Volatilisation and catalytic effects of alkali and alkaline earth metallic species during the pyrolysis and gasfication of Victorian brown coal. Part VIII. Catalysis and changes in char structure during gasification in steam, Fuel 85 1518-1525 (2006).

[28] K Miura, K Hashimoto and P L Silveston. Factors affecting the reactivity of coal chars during gasification, and indices representing reactivity, Fuel 68 1461-1475 (1989). 